\title{
A Performance Evaluation of Four Bar Mechanism Considering Flexibility of Links and Joints Stiffness
}

\author{
A. M. Vaidya ${ }^{*}$ and P. M. Padole \\ Department of Mechanical Engineering, Visvesvaraya National Institute of Technology, Nagpur, India
}

\begin{abstract}
This paper deals with the study of joint clearance on kinematics of mechanism and bearing stiffness along with links flexibility on modal analysis at higher frequency. Literature survey reveals that the studies were carried out for highspeed mechanism considering linkage flexibility without considering bearing stiffness.

The method of calculating clearance at joints, checking for orientation of linkages and estimation of exact mechanical error using sensitivity analysis is discussed. An attempt is also made to analyze the actual dynamic performance of mechanism by determining natural frequencies of flexible mechanism at high speed considering the effect of bearing stiffness. Bearing stiffness depends upon speed, bearing load and also on wear, out of run, play etc during operation. It is observed that as the stiffness of joint increases natural frequency also increases and converges when stiffness reaches a value close to $1.6 \times 10^{9} \mathrm{~N} / \mathrm{m}$.
\end{abstract}

Keywords: Clearance link, bearing stiffness, flexible linkages.

\section{INTRODUCTION}

A mechanical system is made-up of several components, which can be divided into two major groups namely links and joints. The functionality of a joint relies upon the relative motion allowed between the connected components. This implies the existence of a clearance between the mating parts. The joint clearance has motivated a number of investigations on the subject [1-3]. Gilardi G. [1] presented a literature review concerned with contact dynamics taking into account the effects of friction and lubrication. P. Flores et al. [2] have focused on dynamics of joint of slider-crank system with joint clearance. Schwab [3] modeled analytically joint clearances in mechanical systems considering both the dry contact and the lubrication effects.

In the past few years the number of publications, which deal with elastic behavior of mechanisms, has increased considerably. Dwivedy [4] conducted survey of the literature related to dynamic analyses of flexible robotic manipulators for both link and joint flexibility. An effort has been made to critically examine the methods used in these analyses. Turcic $[5,6]$ presented dynamic analysis of elastic mechanism system with experimental validation of analytical methods. S.D Yu and F. Xi [7] presented a methodology for free vibration analysis of flexible mechanisms by modeling a beam with higher-order elements. Yu and Cleghorn [8] dealt with procedure for determining values of critical running speeds that cause a high speed flexible mechanism to become dynamically unstable due to parametric resonance.

Various methods including finite element method, lumpmass method, substructure method and continuum mecha-

*Address correspondence to this author at the Department of Mechanical Engineering, Visvesvaraya National Institute of Technology, Nagpur, India; Tel: 0253-2317869; Fax: 0253-2316955;

E-mail:am_vaidya1@rediffmail.com nics method have been discussed by various researchers. Among other methods, the finite element models have been employed in more general to flexible mechanisms. Flexible links in a mechanism are commonly modeled as elastic beams with and without consideration of the effects of large deformations, shear deformations, rotary inertia and axial deformations. Once modeling of an unconstrained link is completed, the Lagrange multiplier method or the augmented Lagrange equations may be used to formulate the equations of motion for the entire mechanism by enforcing continuity conditions across the interfaces. These differential equations governing the kineto-elastodynamic behaviors of a mechanism are solved directly using numerical or analytical methods to study modal analysis, deflections and stresses in a planar mechanism using a cubic polynomial mode shape.

In the present work, a simple method is presented to estimate the error in the output angle and path generation due to clearance between crank-coupler-follower. Estimation of clearance link, its orientation and bearing stiffness is explained in section 2. Section 3 deals with modal analysis of flexible linkages considering stiffness of joint. Results obtained were compared with results of earlier researchers in Section 4. Conclusions are presented in Section 5.

\section{ESTIMATION OF CLEARANCE LINK}

Linkages in mechanism are connected with bearing as shown in Fig. (1). A bearing comprised of an inner rotating cylinder (JOURNAL) and outer cylinder (BEARING). The two cylinders are closely spaced and angular gap between two cylinders is known as clearance, which is very small as compared to link lengths as shown in Fig. (2). The angle $\delta$ is an angle of clearance link with reference to crank orientation. The clearance in joints does not constrain any degree of freedom in the system; it imposes some kinematics restrictions limiting the journal to move within the bearing. 


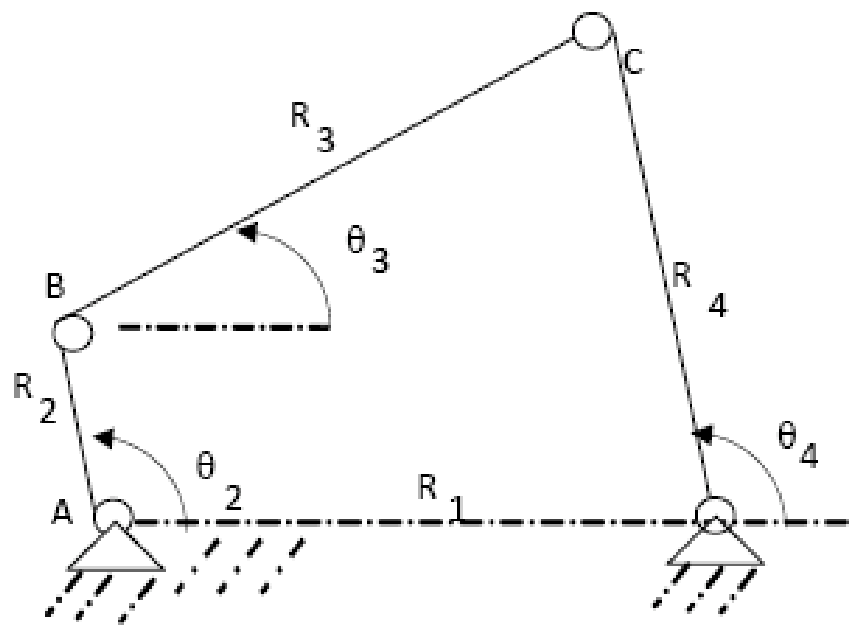

Fig. (1). Four bar linkage without clearance.

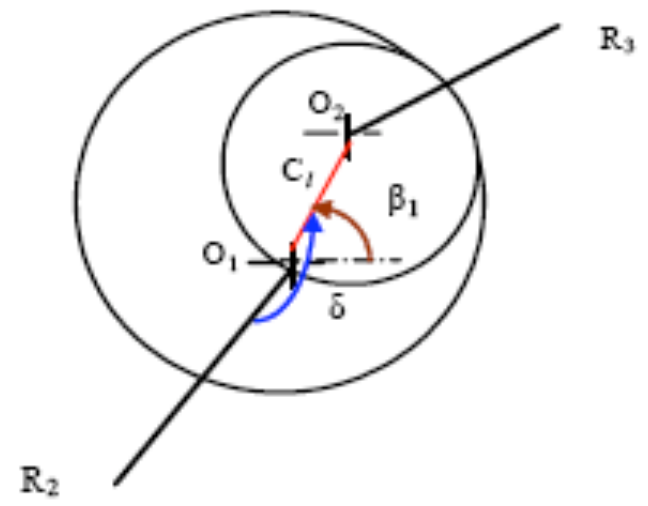

Fig. (2). Clearance link.

The clearance can be allocated from functional point of view or estimated for acceptable deviation in output angle. In this research paper clearance estimated for acceptable deviation in output angle is discussed.

The displacement equation for mechanism can be written using Frudenstein's equation

$\theta_{4}=f\left(\theta_{2}, R_{i}\right)(\mathrm{i}=1 \ldots \ldots .4)$

The deviation in the output angle due to small deviation in the link parameters follows a statistical pattern which can be expressed probabilistically as

$\delta \theta_{4}=\left\{\sum_{i=1}^{4}\left[\left(\partial \theta_{4} / \partial R_{i}\right) \delta R_{i}\right]^{2}\right\}^{1 / 2}$

Where allowable deviations in link parameter and specified output deviation is represented by $\delta \mathrm{R}_{\mathrm{i}}$ and $\delta \theta_{4}$.

Assuming that all tolerance and clearance have the same effect upon output deviation, Eq. 2 will result into

$$
\begin{aligned}
\left(\boldsymbol{\partial} \theta_{4} / \partial R_{1}\right) \delta R_{1}=\left(\partial \theta_{4} / \partial R_{2}\right) \delta R_{2}= & \left(\partial \theta_{4} / \partial R_{3}\right) \delta R_{3} \\
= & \left(\partial \theta_{4} / \partial R_{4}\right) \delta R_{4}
\end{aligned}
$$

On simplifying

$$
\delta R_{i}=\frac{\ddot{a} \grave{\mathrm{e}}_{4}}{\sqrt{4}\left(\frac{\partial \grave{\mathrm{e}}_{4}}{\partial R_{i}}\right)}
$$

The effective distance between the joints of the links is given by

$$
R_{i}=R_{i}+\ddot{a} R_{i}
$$

$\mathrm{R}_{\mathrm{i}}$ is the nominal length of link $\mathrm{i}$ as shown Fig. (3).

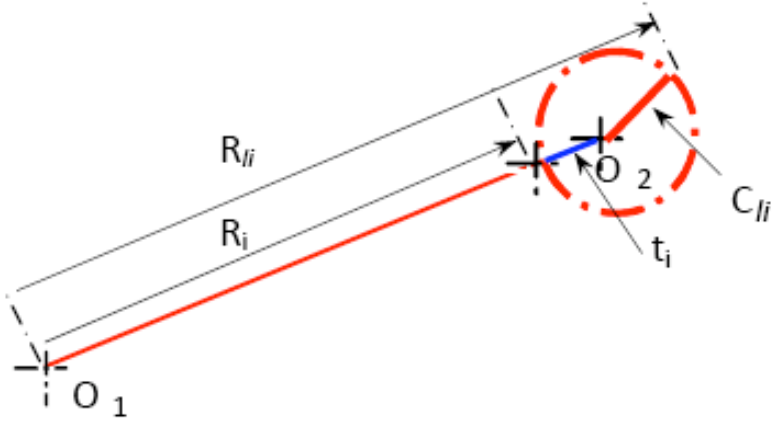

Fig. (3). Details of link.

Total deviation in the link depends upon tolerance in the link $\left(\mathrm{t}_{\mathrm{i}}\right)$ and clearance at the joint $\left(\mathrm{C}_{l i}\right)$. Assuming ratio of clearance to tolerance equal to unity.

$\mathrm{C}_{l \mathrm{i}}=\mathrm{t}_{\mathrm{i}}$

The magnitude of $\delta R_{i}=\sqrt{t_{i}^{2}+C_{l i}^{2}}$

$\Rightarrow t_{i}=C_{l i}=\frac{\delta R_{i}}{\sqrt{2}}$

Eqs. 1-8 can be used to get required tolerances and clearance on link lengths for specified error in output angle.

\subsection{Effect of Joint Clearance on the Orientation of Linkages}

It has been observed that, in single loop linkage, joint clearances with same value contribute equally to deviation of the link from its ideal position [9]. It is possible to asses the output position or direction variation, due to clearances allocated at the joints, by using geometrical model.

Let each joint clearance represented by a clearance link $\mathrm{C}_{l}$, an N-bar linkage is equivalent to a (2N)-bar linkage and the number of Degree of freedom (DOF) is increased from $(\mathrm{N}-3)$ to $(2 \mathrm{~N}-3)$. Because the sum of all clearance link lengths is much smaller than any nominal link length, adding clearance links does not change the classification of the resulting chain, the linkage becomes one with an eight-bar chain including four clearance links as shown in Fig. (4). It may be noted that the expression $R_{4}+R_{1}<R_{2}+R_{3}$ for ideal 
mechanism is equivalent to $\mathrm{R}_{4}+\left(\mathrm{R}_{1}+4 \mathrm{C}_{l}\right)<\left(\mathrm{R}_{2}+\mathrm{R}_{3}\right)$ for mechanism considering clearance linkages.

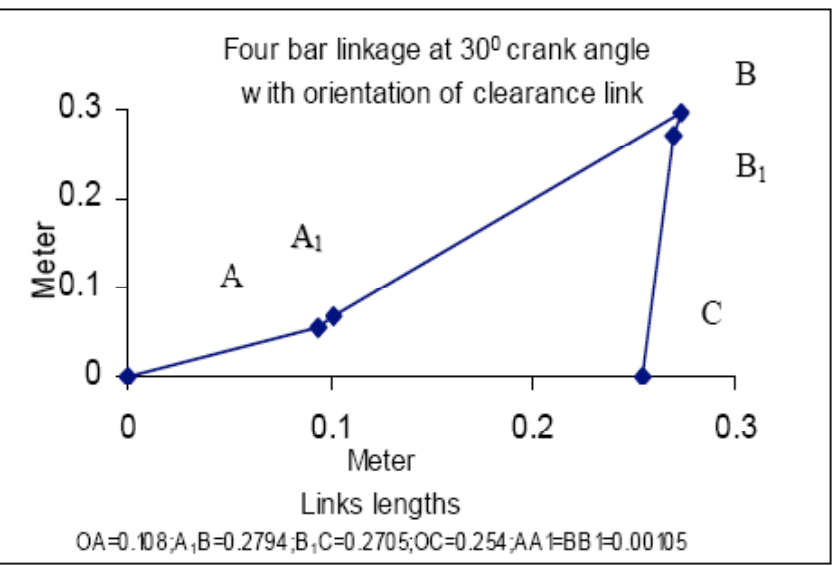

Fig. (4). Linkages with clearance at both end of coupler.

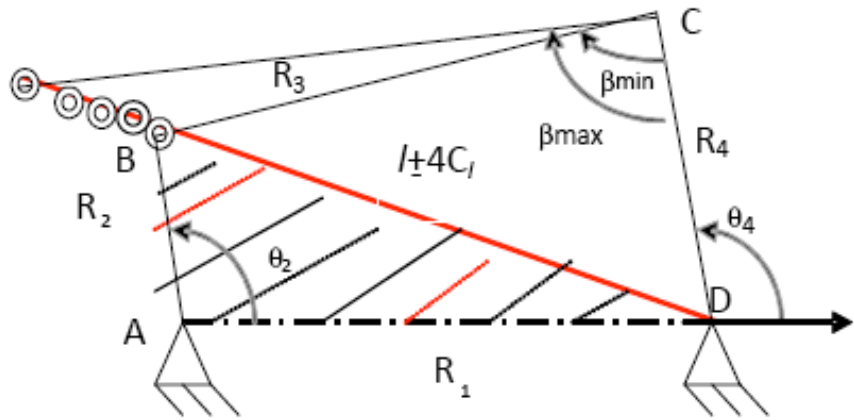

Fig. (5). The limiting value of $\beta$.

As shown in Fig. (5), sum of all clearance links to diagonal line BD gives two angles between coupler and follower. The length of diagonal $(l)$ is given by cosine formula as

$l=\sqrt{R_{1}^{2}+R_{2}^{2}-2 R_{1} R_{2} \operatorname{Cos} \theta_{2}}$

The possible range of angle $\beta$ can be found between $\beta_{\min }$ and $\beta_{\max }$ as

$$
\beta_{\text {min,max }}=\cos ^{1} 22\left\{\left[R_{4}^{2}+R_{3}^{2}-\left(l \pm 4 C_{l}\right)^{2}\right] /\left(2 R_{4} R_{3}\right)\right\}
$$

The proposed method makes it possible for designers to predict and set the limits of the uncertain range within the desired safety range by estimating the clearance value.

\subsection{Orientation of the Clearance Link $\left(\beta_{1}\right)$}

Once the clearance has been estimated for the joints of four bar mechanism, its orientation can be obtained from joint forces between the links of mechanism. The joint forces are obtained from the kinematics and dynamics analysis of four bar mechanism with the assumption of rigid-body motion of all linkages and zero clearance in all joints.

$\beta_{1}=\tan ^{-1}\left(\mathrm{~F}_{\mathrm{y}} / \mathrm{F}_{\mathrm{x}}\right)$

\subsection{Sensitivity Co-efficient and Mechanical Error}

Clearance links affect kinematics performance of linkages. Jae Kun Shin and Jin Han Jun [10] presented a general method of finding mechanical error using sensitivity coefficients for one revolution of clearance link at fixed crank angle. The method transforms the problem of calculating sensitivity coefficients into one of the velocity analysis. The pattern of the error is elliptical for one cycle of clearance link. In the present work however the exact orientation of clearance link is determined for a given crank angle as explained in Sec.2.2. Using this clearance link and its orientation, exact error has been calculated [11]. Mechanical error of the path point $P$ resulting from a clearance at the pin joint B (Fig. 6) is defined as:

$E_{p}(r, \delta)=R_{p}(r, \delta)-R_{p}(0, \delta)$

$\mathrm{r}$ and $\delta$ represents the relative position of the pin within clearance circle (Fig. 2). As the magnitude of the clearance remains small compared to the lengths of links. $R_{p}(r, \delta)$ can be approximated by Taylor's series

$$
R_{p}(r, \delta)=R_{p}(0, \delta)+\left.\frac{\partial R_{p}}{\partial r}\right|_{(0, \delta)} r
$$

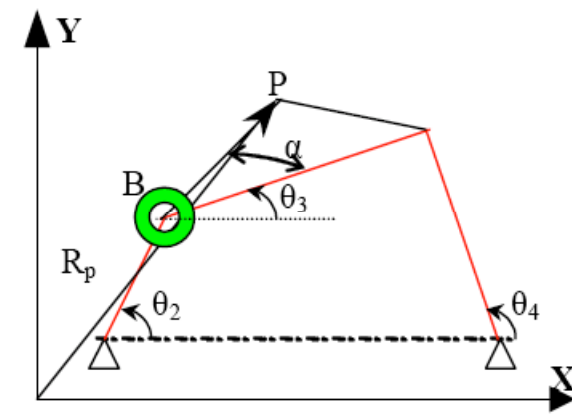

Fig. (6). Four bar mechanism with clearance at B-joint.

Eqs. 12 and 13 give

$$
E_{p}(r, \delta)=\left.\frac{\partial R_{p}}{\partial r}\right|_{(0, \delta)} r
$$

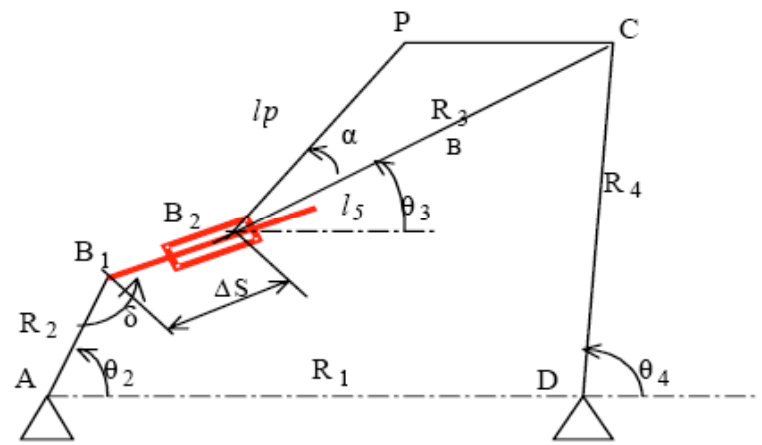

Fig. (7). Sensitivity linkage for the clearance.

The term $\partial \mathrm{R}_{\mathrm{p}} / \partial \mathrm{r}$ is known as sensitivity co-efficient. Sensitivity linkage is formed by adding, two more links to the original four bar mechanism (Fig. 7). A slider ' $\mathrm{S}$ ' is pinned at $\mathrm{B}_{2}$ and a link ' $l_{5}$ ' through the slider is pinned at $\mathrm{B}_{1}$ 
to get a new linkage of 3-DOF. Let ' $l_{5}$ ' be fixed relative to the input link by an angle $\delta$. Then sensitivity coefficients is given by input velocity.

$$
\begin{aligned}
& \left.\frac{\partial R_{p}}{\partial r}\right|_{(0, \delta)}=\Delta s \rightarrow 0\left(\frac{\Delta R_{p}}{\Delta S}\right) \\
& =\Delta s \rightarrow 0\left(\frac{\lim _{p} / \Delta t}{\Delta S / \Delta t}\right)=V_{p} / S^{1}
\end{aligned}
$$

Required velocity ratio can be obtained by setting slider input velocity equal to one and Eq.15 will be

$$
\left.\frac{\partial R_{p}}{\boldsymbol{\partial} r}\right|_{(0, \delta)}=\left.V_{p}\right|_{\theta_{2}=\theta_{2} ; \delta=\delta ; S^{1}=S^{1}}
$$

$\mathrm{X}-\mathrm{Y}$ component of mechanical error $E_{p x}=V_{p x} C_{l}$;

$$
E_{p y}=V_{p y} C_{l}
$$

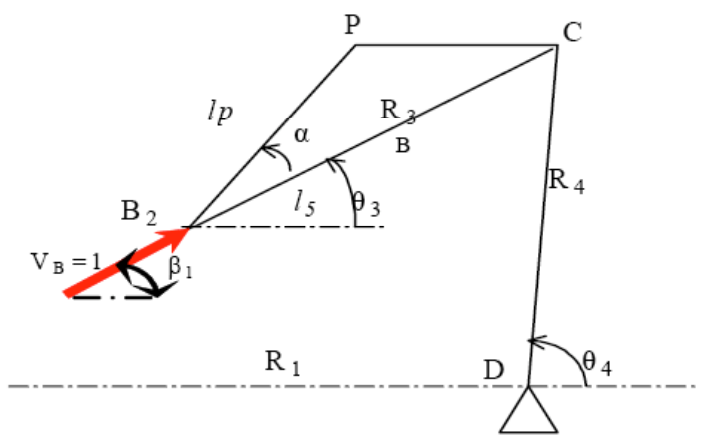

Fig. (8). Open kinematics chain.

Resultant of $\mathrm{E}_{\mathrm{px}}$ and $\mathrm{E}_{\mathrm{py}}$ and its orientation $\left(\theta_{\mathrm{Ep}}\right)$ will be

$T E_{p}=\sqrt{E_{p x}^{2}+E_{p y}^{2}} ; \theta_{E p}=\tan ^{-1}\left(E_{p y} / E_{p x}\right)$

As shown in Fig. (8), the magnitude of $R_{p}$ (position vector for point $\mathrm{P}$ ) without clearance $\mathrm{R}_{\mathrm{p}(\mathrm{Cl}, 0)}$ is obtained as

$R p=\sqrt{R_{p x}^{2}+R_{p y}^{2}}$

Position of coupler point $\mathrm{P}_{1}$, refer Figs. (8 and 9), from origin because of clearance between crank and coupler $\mathrm{R}_{\mathrm{p}(\mathrm{Cl}, \beta)}$ will be

$$
R_{p(c l, \beta)}=\sqrt{R_{p(C l, 0)}^{2}+T E_{p}^{2}-R_{p(C l, 0)} T E_{p} \operatorname{Cos}(\Omega)}
$$

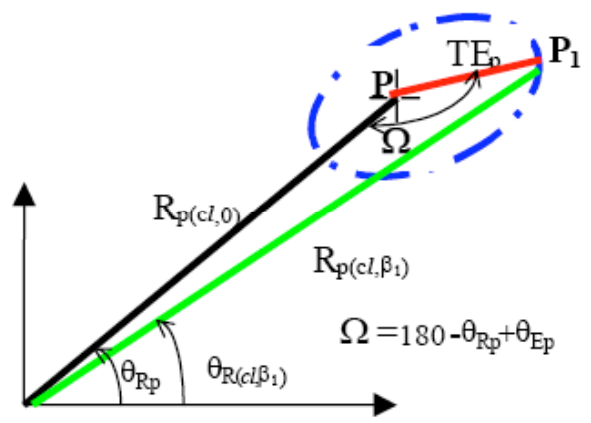

Fig. (9). Magnitude of coupler point with mechanical error.

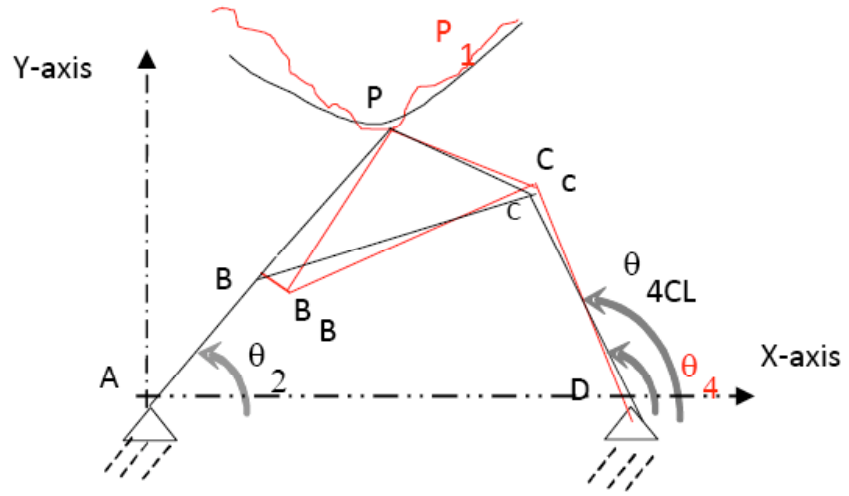

Fig. (10). Four bar linkage with and without clearance.

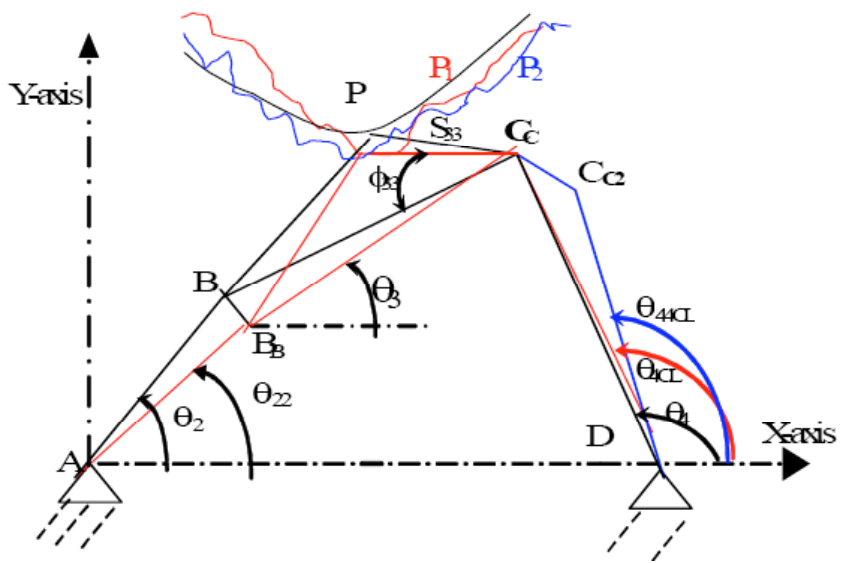

Fig. (11). Four bar linkage with clearance at joints at joint crank and coupler (Joint-1) Crank-Coupler-Follower (Joint-1 and Joint-2).

The orientated clearance link $(\delta)$ at crank-coupler B-B $\mathrm{B}_{\mathrm{B}}$ (Fig. 10) causes the journal center between coupler and follower to shift from $C$ to $C_{c}$ which causes the error in output angle from $\theta_{4}$ to $\theta_{4 \mathrm{cl}}$ and coupler point shift from $\mathrm{P}$ to $\mathrm{P}_{1}$. Similarly clearance link at coupler-follower $\mathrm{C}_{\mathrm{c}}-\mathrm{C}_{\mathrm{c} 2}$ (Fig. 11) causes further error in output angle $\theta_{4 \mathrm{cl}}$ to $\theta_{44 \mathrm{cl}}$ and coupler point curve shift from $\mathrm{P}_{1}$ to $\mathrm{P}_{2}$. To obtain the said parameters computer code has been developed. It is observed that obtained error was minimum for optimum transmission angle which is ranging from $60^{\circ}-288^{\circ}$ crank angle. Also, clearance links at both end of coupler are used to find total error in the path and function generation.

Clearances in the bearing not only affect kinematics performance but also modal performance of linkages. By knowing the fluctuation of forces at bearing, bearing stiffness can be model as a linear spring using clearance link as discussed in following section.

\subsection{Bearing Stiffness}

The literature survey indicates that during analysis of elastic linkages bearings have been considered as ideal i.e. without any clearance and elasticity. However, clearance in bearing induces error both in path generation, function generation and also affect the stiffness property of bearing.

Bearings are subjected to horizontal and vertical vibrations due to the joint and unbalance forces. The shaft or journal center always moves about an equilibrium position described by eccentricity (e) and eccentricity angle $(\varphi)$ as shown in Fig. (12). However, the orbit of the shaft motion is 
small compared to the bearing clearance. Three different types of motion between the journal and bearing can be observed during the dynamics of the revolute joint namely, (i) permanent contact, in which contact is always maintained although the relative penetration depth between the bearing and journal varies along the circumference of the journal; (ii) impact mode, which occurs at the termination of the free flight mode, being impact forces applied to and removed from the system; (iii) free flight mode, in which the journal moves freely within the bearing's boundaries, that is, the journal and the bearing are not in contact. Bearing can be dynamically represented as spring in liberalized model to represent the stiffness. Stiffness coefficient depends on journal speed, load and have significant implication during operation.

For free flight mode, the positive spring constant or stiffness as shown in Fig. (13), is defined as the amount of force that is required to obtain a unit displacement in a particular direction. The fluid film forces are functions of journal center displacements and velocities. It is assumed that the journal is subjected to small displacements, which are less than the bearing clearance. The bearing forces can be expressed by Taylor series expansion around the journal.

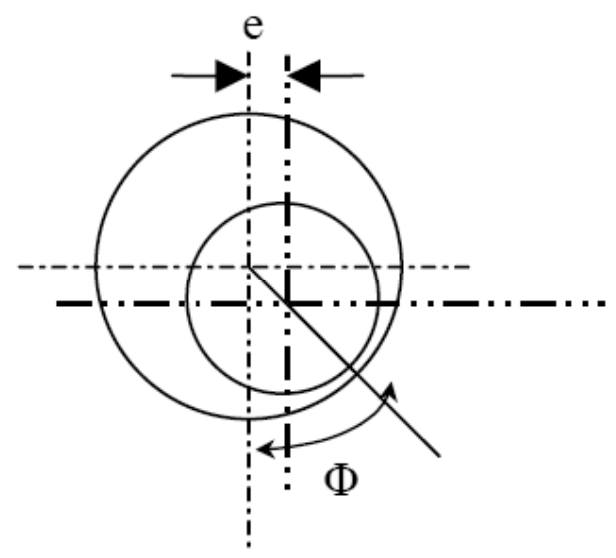

Fig. (12). Equilibrium position.

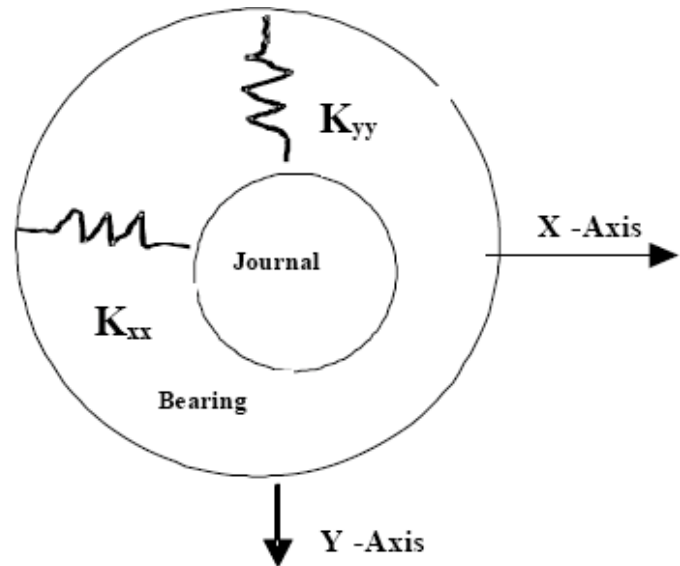

Fig. (13). Dynamic properties of bearing.

$$
\begin{aligned}
F_{x}=F_{x 0}+\left(\delta F_{x} / \delta X\right) \Delta X+\left(\delta F_{x} / \delta Y\right) \Delta Y \\
+\left(\delta F_{x} / \delta \dot{X}\right) \Delta \dot{X}+\left(\delta F_{x} / \delta \dot{Y}\right) \Delta \dot{Y}
\end{aligned}
$$

$$
\begin{aligned}
F_{y}=F_{y 0}+(\delta F y / \delta X) \Delta X+\left(\delta F_{y} / \delta Y\right) \Delta Y \\
+\left(\delta F_{y} / \delta \dot{X}\right) \Delta \dot{X}+\left(\delta F_{y} / \delta \dot{Y}\right) \Delta \dot{Y}
\end{aligned}
$$

When the journal is subjected to a small displacement in either the $\Delta \mathrm{X}$ or $\Delta \mathrm{Y}$ direction, a corresponding change in force occurs in both $\Delta \mathrm{F}_{\mathrm{x}}$ and $\Delta \mathrm{F}_{\mathrm{y}}$ directions. Thus, stiffness can be defined as in Eqs. 22 and 23.

$$
\begin{gathered}
K_{i j}=\Delta F /\left(.05 * C_{l}\right) ; \mathrm{ij}=\mathrm{x}, \mathrm{y} \\
K_{x x}=\Delta F_{x} / \Delta x ; K_{y y}=\Delta F_{y} / \Delta y
\end{gathered}
$$

The perturbation constants selected are the fractional amounts of journal displacement from the equilibrium point used in calculating the stiffness coefficients. Over the small changes on the journal position or motion, the dynamic coefficients will be approximately constant and given by $.05 \mathrm{C}_{l}[12]$. Thus perturbation constant defined as

$\Delta \mathrm{X}=\Delta \mathrm{Y}=0.05 \mathrm{C}_{l}$

$\mathrm{C}_{l}$ is clearance.

Eqs. 22-24 indicate that bearing stiffness depend upon change in force and clearance value. For free flight mode, bearing stiffness values varying from $2.5 \times 10^{4} \mathrm{~N} / \mathrm{m}$ to $1.56 \times 10^{9} \mathrm{~N} / \mathrm{m}$.

During permanent contact or impact mode, the generalized stiffness parameter $\mathrm{K}$ depends on the geometry and physical properties of the contacting surfaces. For two spherical contacting bodies with radii $R_{i}$ and $R_{j}$, the stiffness parameter is expressed by

$$
K=\frac{4}{3 \pi\left(\sigma_{i}+\sigma_{j}\right)}\left[\frac{R_{i} R_{j}}{R_{i}-R_{j}}\right]^{1 / 2}
$$

in which the material parameters $\sigma_{\mathrm{i}}$ and $\sigma_{\mathrm{j}}$ are given by

$\sigma_{z}=\frac{1-\nu_{z}^{2}}{E_{z}} ;(z=i, j)$

Variables $v_{\mathrm{z}}$ and $\mathrm{E}_{\mathrm{z}}$ are the Poisson's coefficient and the Young's modulus associated with each body, respectively. The radius of curvature is taken as positive for convex surfaces and negative for concave surfaces [13]. In Eq. 25, the value $\left(\mathrm{R}_{\mathrm{i}}-\mathrm{R}_{\mathrm{j}}\right)$ represent clearance value. The sphere with radius $\mathrm{R}_{\mathrm{i}}=8.95 \mathrm{~mm}, \mathrm{R}_{\mathrm{j}}=-10 \mathrm{~mm}, \mathrm{E}=2.06 \times 10^{11} \mathrm{~N} / \mathrm{m}^{2}$ and Poisson's coefficient $v=0.3$ value of stiffness $1.5 \times 10^{11} \mathrm{~N} / \mathrm{m}$.

The bearing has to overcome torsional stiffness of the link attached. The compliance for torsional stiffness of link attached is represented by a torsional spring. The torsional spring constant $\mathrm{K}_{\mathrm{t}}$ for a cantilever beam with a force at the free end is given by [14].

$\mathrm{K}_{\mathrm{t}}=\gamma \mathrm{K} \varphi \mathrm{EI} / l$

Where $\mathrm{E}$ is the Young's Modulus, $\mathrm{I}$ is the area moment of inertia, 1 is the beam length and $\mathrm{K}_{\Phi}$ is the pseudo-rigid-body model stiffness coefficient, which has the value of $\mathrm{K}_{\mathrm{t}}=2.65$ and $\gamma=0.85$. 
Using above expressions, values of linear and torsional stiffness are calculated. Linear spring stiffness values are chosen from $4.5 \times 10^{5} \mathrm{~N} / \mathrm{m}$ to $1.6 \times 10^{9} \mathrm{~N} / \mathrm{m}$ depending upon different types of motion. These values are cross checked with the values given in the literature and available software for numerical values for rotor dynamic coefficients for constant speed and load.

\section{FINITE ELEMENT MODELING OF FOUR BAR MECHANISM}

The mathematical model of four bar flexible linkages must generally capture the mass and stiffness charactertics of links using Lagrang's equation and theory from structural mechanics. Generally 2D-Euler's beam element is selected for system-oriented element matrices. Research dealing with dynamic behavior of four bar crank-rocker mechanism containing elastic effects has been carried out since long. Researchers treated elastic links as continuous system or as discrete system. The finite element theory of structural analysis or lumped parameter approach has been applied for modeling an elastic linkage using force method or the displacement method. Using various analysis methods, researchers have verified their respective techniques by conducting experimental investigations. The main assumption made in the analysis are (i) frictionless bearing representing free-free motion between journal and bearing (ii) no play in the bearings (iii) small elastic deformation from rigid-body equilibrium position (iv) constant crank speed.

However, in reality motion between bearing and journal is governed by dynamics of bearing due to joint forces, hydrodynamic forces etc. Hence in present work, bearing is represented by linear and torsional spring constant as discussed in section 2.4. The effects of these stiffnesses on modal analysis are studied and results are compared with analytical method available for dynamic response of elastic mechanisms presented by D.A Trucic [5, 6].

Eq. 27 shows the motion of the elastic beam element described by Lagrange's Equation,

$$
\frac{d}{d t}\left(\frac{\partial K E_{i}}{\partial\{\dot{U}\}_{i}}\right)-\frac{\partial K E_{i}}{\partial\{U\}_{i}}+\frac{\partial P_{i}}{\partial\{U\}_{i}}=\{Q\}_{i}+\{F\}_{i}
$$

$\{U\}_{\mathrm{i}}$ represents the generalized nodal DOF, $\mathrm{KE}_{\mathrm{i}}$ is kinetic energy of the element, $P_{i}$ is potential energy, $\{Q\}_{i}$ the generalized forces acting on the element, $\{F\}_{i}$ applied external forces.

Eq. 27 is used to develop the element mass and stiffness matrix as given in Eq. 28.

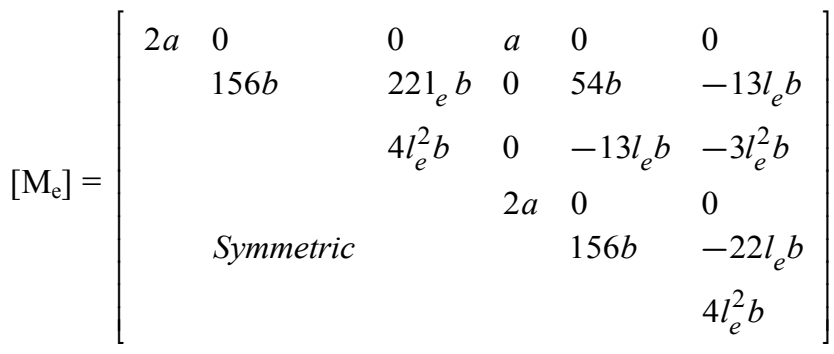

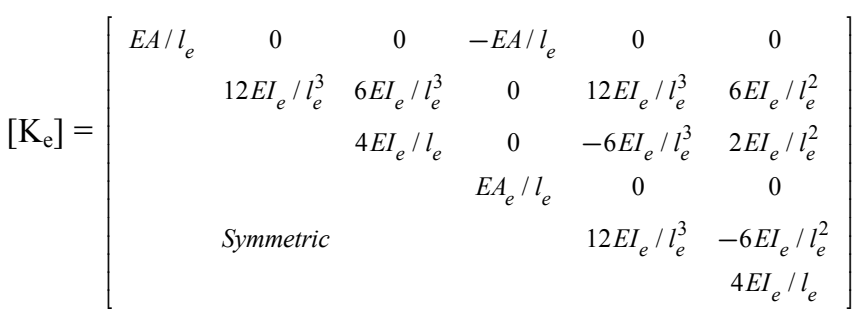

where $a=\frac{\rho A_{e} l_{e}}{6}, b=\frac{\rho A_{e} l_{e}}{420}$

The above mass and stiffness matrices are for individual elements in their local coordinates. These elements matrices in the global coordinate system can be defined using transformation matrix [R].

$$
[\mathrm{R}]=\left[\begin{array}{cccccc}
\lambda & \mu & 0 & 0 & 0 & 0 \\
-\mu & \lambda & 0 & 0 & 0 & 0 \\
0 & 0 & 1 & 0 & 0 & 0 \\
0 & 0 & 0 & \lambda & \mu & 0 \\
0 & 0 & 0 & -\mu & \lambda & 0 \\
0 & 0 & 0 & 0 & 0 & 1
\end{array}\right]
$$

as $[\mathrm{m}]=[\mathrm{R}]^{\mathrm{T}}\left[\mathrm{m}_{\mathrm{e}}\right][\mathrm{R}] ;[\mathrm{k}]=[\mathrm{R}]^{\mathrm{T}}\left[\mathrm{k}_{\mathrm{e}}\right][\mathrm{R}]$

where $\lambda=\operatorname{Cos} \theta: \mu=\operatorname{Sin} \theta$ and $\theta$ is the orientation of element with reference to global co-ordinate system.

To simplify the computational, assumptions made are:

Each link is modeled by one finite-beam element.

The input shaft is assumed to be connected to a flywheel with high inertia, ensuring that no undue fluctuations occur in the input angular velocity.

The input crank is treated as "instantaneous structure" in each position of the moving mechanism for one cycle.

In earlier work to simulate a pin joint between adjacent links two independent rotational deformation in each of the two elements were chosen. These two independent deformations represent free-free motion between adjacent links (bearing and journal). However, here joints are modeled by assigning suitable linear and torsional stiffness. A total system oriented global stiffness matrix of linkage is suitably modified by adding these stiffnesses at appropriate positions.

As shown in Fig. (14), system-oriented generalized displacements are labeled to describe the structural deformations of the linkage as well as to maintain compatibility between the elements at the node (bearing joint). For example, at node $B, U_{4}$ and $U_{5}$ are required to describe the nodal translations from the rigid-body position of linkage, two more independent displacements, $U_{6}$ and $U_{7}$, are necessary at node $\mathrm{B}$ to describe the rotational deformations in each of the two elements, 1 and 2 with respect to their respective rigid-body orientations. In earlier papers movement between journal and bearing was considered as free-free. Actually, the movement is controlled by forces and clearance link of bearing, which can be represented by spring stiffness. The joint characteristic is represented by stiffness values of 
joint and adding to respective generalized displacements $\left(\mathrm{U}_{4}\right.$, $\mathrm{U}_{5}$ and $\mathrm{U6}$ ) as shown in Fig. (15).

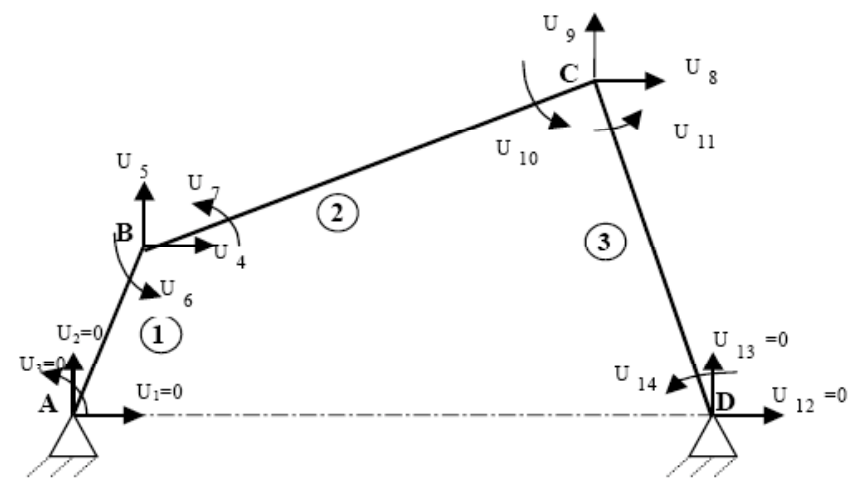

Fig. (14). Elastic mechanism with 3-Elements and 9-DOF.

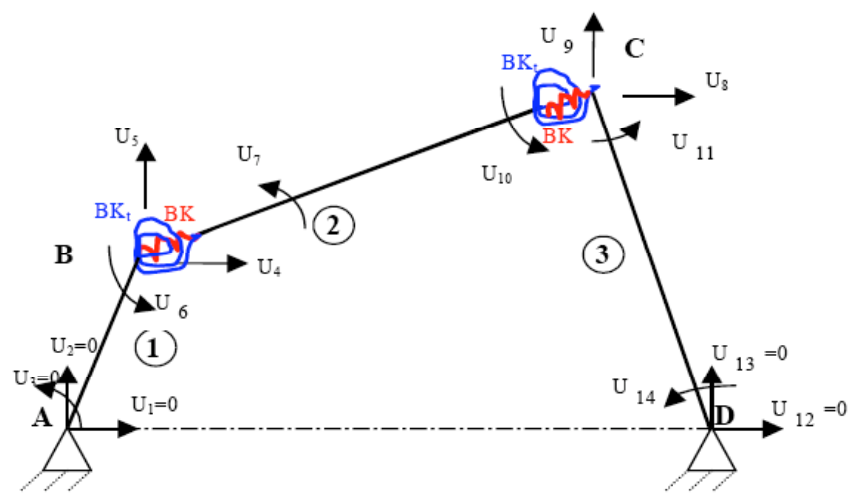

Fig. (15). Elastic mechanism 3-Elements and 9-DOF with flexible Bearing $\left(\mathrm{BK} \& \mathrm{BK}_{\mathrm{t}}\right)$.

The total system stiffness matrix $[\mathrm{K}]$ is derived as shown in Eq. 30 by superpositioning and considering the required displacements with bearing stiffness at appropriate locations.

$[\mathrm{K}]=$

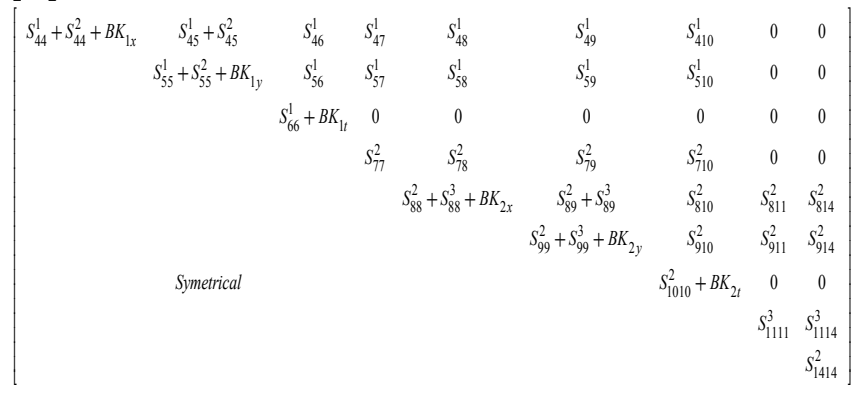

In above equation only non-zero generalized coordinates have been labeled. The first element of above stiffness matrix $\left(\mathrm{S}_{44}^{1}+\mathrm{S}_{44}^{2}+\mathrm{BK}_{\mathrm{x}}\right)$ corresponds to the stiffness for displacement vector $\mathrm{U}_{4}$ of element $1\left(\mathrm{~S}_{44}{ }_{44}\right), \mathrm{U}_{4}$ of element 2 $\left(\mathrm{S}^{2}{ }_{44}\right)$ and $\mathrm{BK}_{1 \mathrm{x}}$ stiffness of bearing in X-direction. The superscripts 1 are added to represent stiffness matrix elements of the element numbered 1 .

After idealization of linkage structure and systemorientated element mass and stiffness matrices; the next step is to obtain the natural frequencies and natural modes of a system, undamped free vibration equation is used because the damping has very little influence on the natural frequen- cies of a system. From the free vibration of the system the following modal equation is solved.

$[M]\{\ddot{U}\}+[K]\{U\}=0$

For the free vibration of the system, modal Eq. 31 will be,

$\left([\mathrm{K}]-\lambda_{\mathrm{i}}[\mathrm{M}]\right)\left\{\mathrm{X}_{\mathrm{i}}\right\}=\{0\}(\mathrm{i}=1,2,3 \ldots \ldots, \mathrm{n})$

The condition of Non-zero solution of Eq. 32 is,

||$[\mathrm{K}]-\lambda_{\mathrm{i}}[\mathrm{M}] \mid=\{0\}$

$(\mathrm{i}=1,2,3 \ldots \ldots, \mathrm{n})$

From Eq. 32 we can obtain the eigenvalues $\lambda_{i}(i=1,2, \ldots$, n) of the system and $\lambda_{i}=\omega_{1}{ }^{2}$. The cyclic frequency $f_{1}=\omega / 2 \pi$ Hertz. By substituting each eigenvalue $\lambda i$ into Eq.33, the eigenvector $\left\{X_{i}\right\}$ or the $i^{\text {th }}$ natural mode of the system can be determined. The modal matrix is defined as,

$[\phi]=\left[\left\{X_{1}\right\},\left\{X_{2}\right\},\left\{X_{3}\right\}-----\left\{X_{n}\right\}\right]$

Natural frequencies (First to Fifth) for mechanism are obtained by solving stiffness and mass matrix using Jacobi Program by accommodating the stiffness of joint. The stiffness of joints is incorporated by changing the stiffness values of joints for axial and transverse directions also the stiffness of pseudo coupler link is added to represent the torsional stiffness as given by Eq. 26 .

A complete Computer code FLBMA (FLEXIBLE LINKAGE-BEARING MODAL ANALYSIS) is developed as per the flowchart shown in Fig. (16) to find mechanical error due to clearance in joints and to carry modal analysis of linkages considering bearing stiffness for one end and both ends of coupler. The programme is developed using Fortran77 for kinematic and dynamic analysis while for modal analysis Turbo-C compiler is used. A total 36305 statements are executed by FORTRAN program with time of execution $0.06 \mathrm{~S}$.

\section{NUMERICAL RESULTS}

In this section, for above listed procedure, numerical simulations are performed for a mechanism selected on a case study. Obtained results are compared for flexible mechanism. The geometrical and material properties for a mechanism are presented in Table $\mathbf{1}$.

Table 1. Details of Four Bar Mechanism

\begin{tabular}{|c|c|c|c|}
\hline & Crank & Coupler & Follower \\
\hline \hline Length $\left(\mathrm{R}_{\mathrm{i}}\right) ; \mathrm{cm}$ & 10.80 & 27.94 & 27.05 \\
\hline Area $\left(\mathrm{A}_{\mathrm{i}}\right) ; \mathrm{cm}^{2}$ & 1.077 & 0.406 & 0.406 \\
\hline $\begin{array}{c}\text { Area Movement of } \\
\text { inertia; } \mathrm{cm}^{4}\end{array}$ & $1.616^{*} 10^{-2}$ & $8.674^{*} 10^{-4}$ & $8.674 * 10^{-4}$ \\
\hline Fixed pivots; cm & 25.4 & & \\
\hline $\begin{array}{c}\text { Modulus of Elasticity; } \\
\mathrm{kPa}\end{array}$ & $7.10^{*} 10^{7}$ & & \\
\hline Clearance; cm & 0.105 & & \\
\hline
\end{tabular}

Position of coupler Point $(\mathrm{P}) \alpha=38^{\circ}$ w.r.t. coupler link and $\mathrm{lp}=5.0 \mathrm{~cm}$. Weight density of links $2.66^{*} 10^{-2} \mathrm{~N} / \mathrm{cm}^{3}$. Weight of bearing $0.42 \mathrm{~N}$. RPM of crank is 340 . 

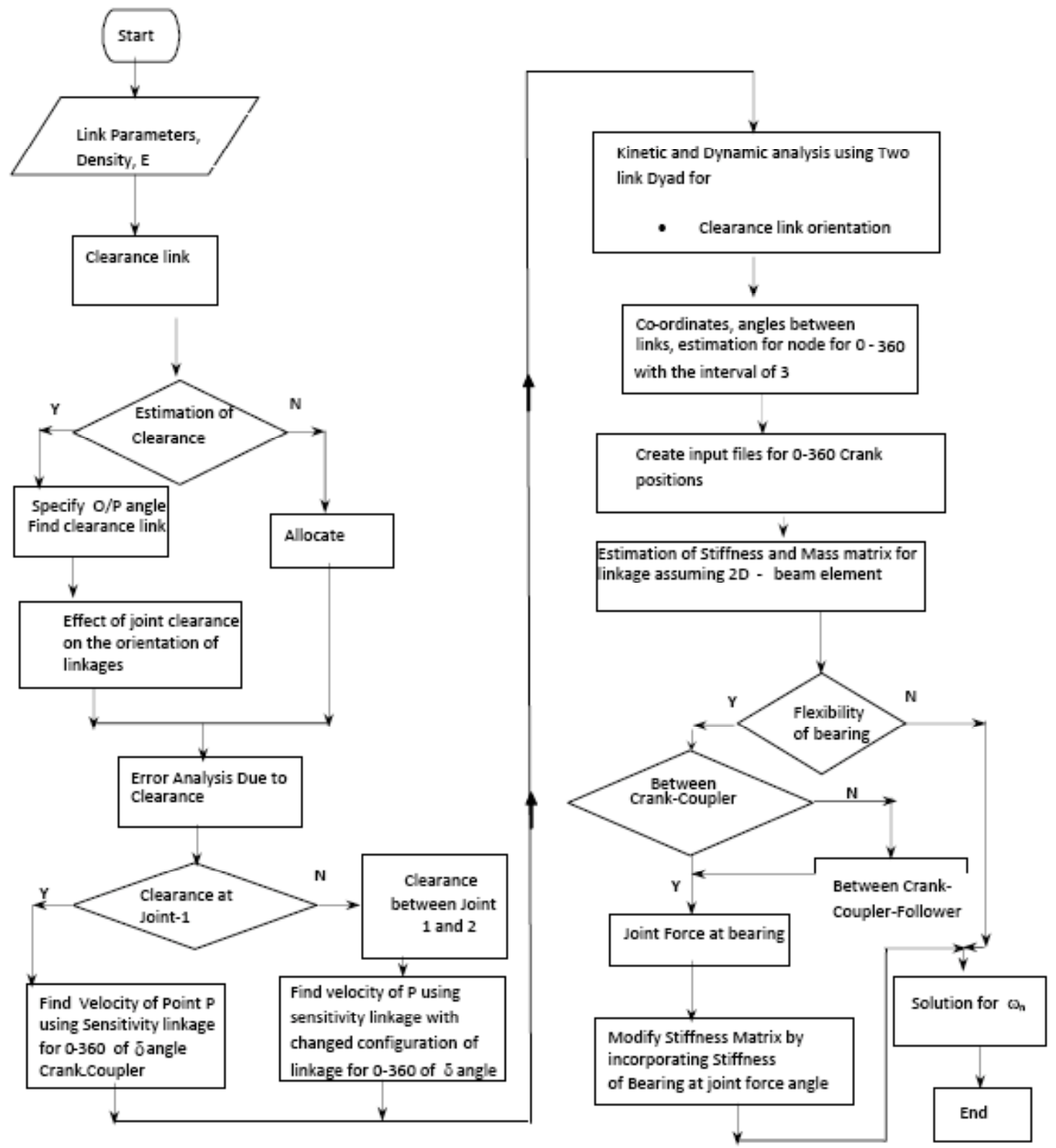

Fig. (16). Flow chart for procedure used in development of computer code.

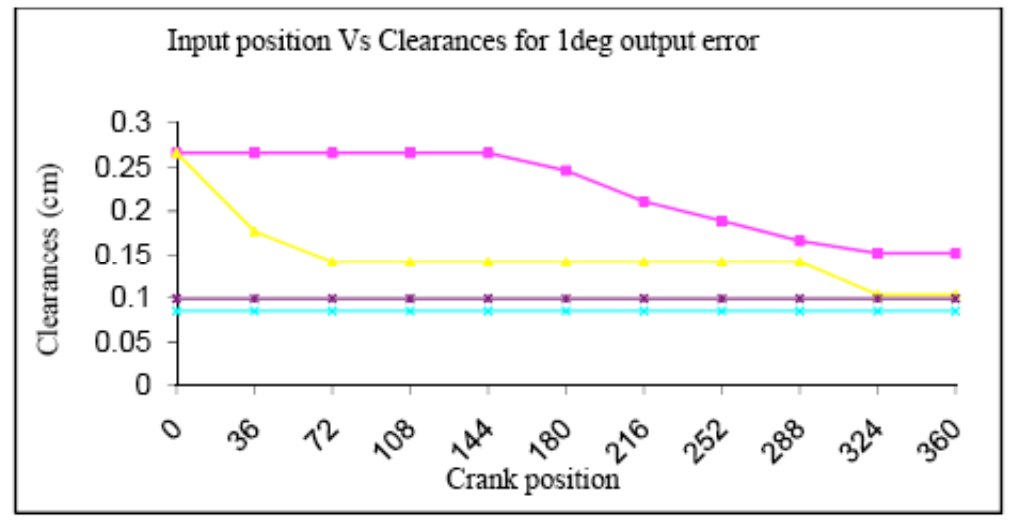

Fig. (17). Crank Angle vs. magnitude of clearance.

The magnitude of clearances on each joint of mechanism for $1^{\circ}$ error in output angle is obtained using procedure of section 2 and depicted (Fig. 17). Clearance link between joint $R_{1}-R_{2}$ is ranging from 0.266 to $0.125 \mathrm{~cm}$, between joint $R_{2}-R_{3}$ is ranging 0.266 to $0.105 \mathrm{~cm}$ and between joint $R_{3}-R_{4}$ and $\mathrm{R}_{4}-\mathrm{R}_{1}$ is constant. 
As joint clearance affect configuration of linkages from its ideal positions, obtained clearances are checked as per section 2.2 for ensuring the mobility and characteristics of mechanism. Results are given in Fig. (18) for coupler angle $\theta_{3}$ and clearance link of magnitude $0.105 \mathrm{~cm}$. It shows that due to addition of clearance links at point $\mathrm{B}$ as shown in Fig. (5), coupler angle $\theta_{3}$ deviate by $1.8^{\circ}$ in the present case.

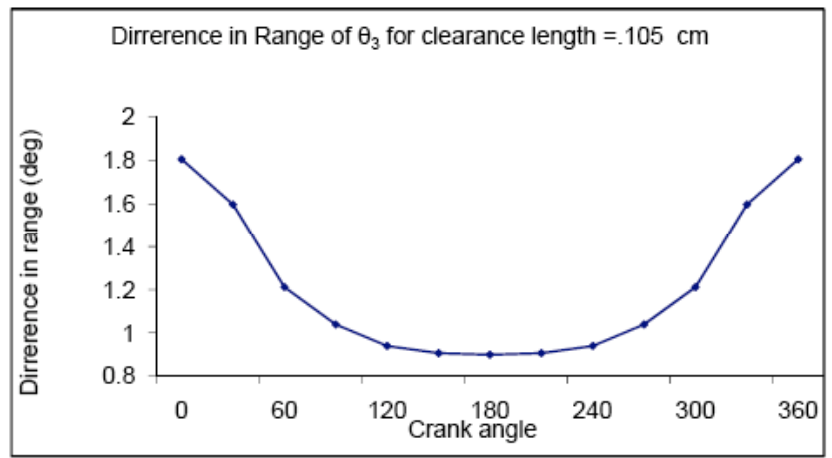

Fig. (18). Difference in Range of $\theta_{3}$.

The mechanical error, for constant crank angle of $150^{\circ}$ and one complete revolution of clearance link is elliptical in nature as shown in Fig. (19).

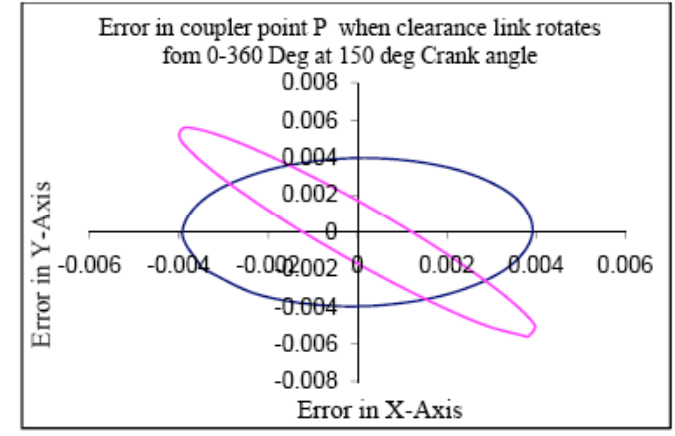

Fig. (19). Distribution of Error at $\Theta_{2}=150^{\circ}$ and $\delta$ varies $0-360^{\circ}$ for coupler point.

For exact estimation of mechanical error, the angle $\delta$ is obtained through kinematics and dynamic of given mechanism [11]. The results are obtained for rigid body angular velocity and acceleration of coupler and follower for constant anticlockwise crank angular velocity of 340rpm $(35.6 \mathrm{rad} / \mathrm{s})$. The joint forces are obtained with assumption of

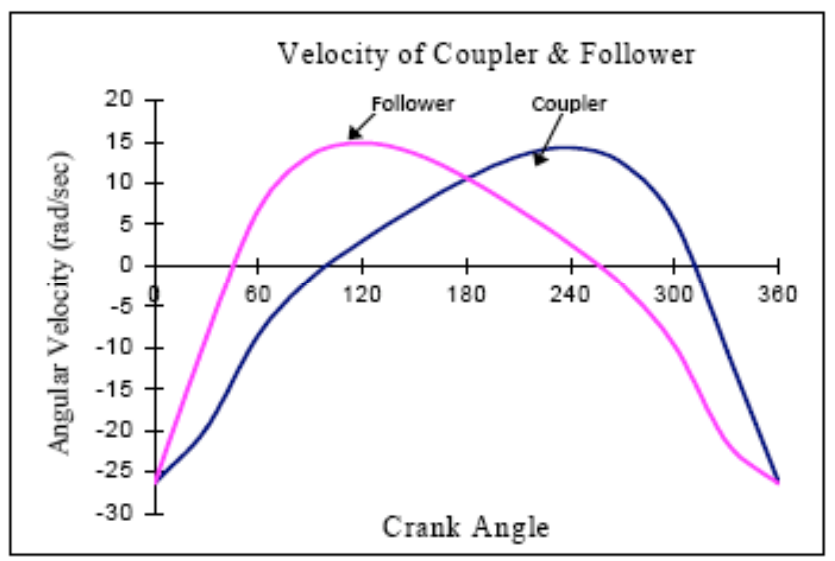

Fig. (20a). Velocity analysis. zero clearance in all joints. Detail results for velocity, acceleration of coupler and follower, components of joint forces at crank-coupler (Joint-1) are presented in Fig. (20ac).

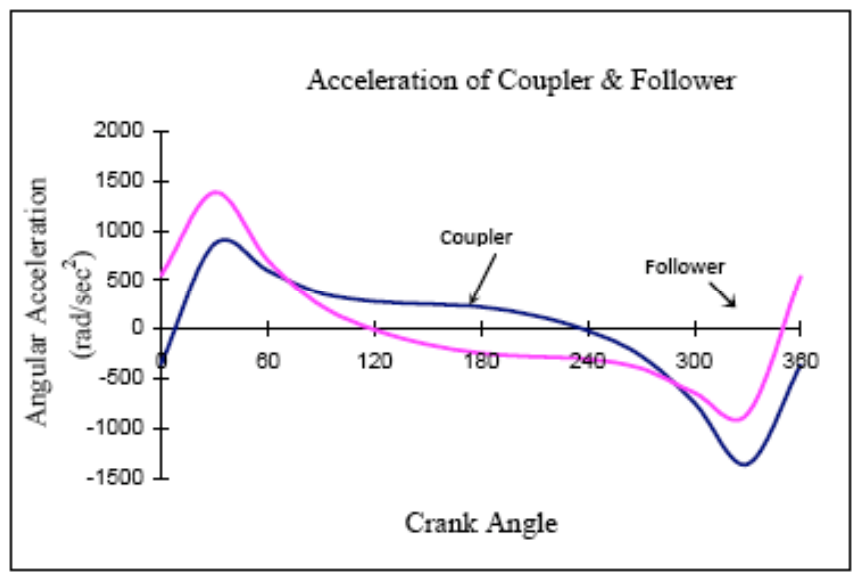

Fig. (20b). Acceleration analysis.

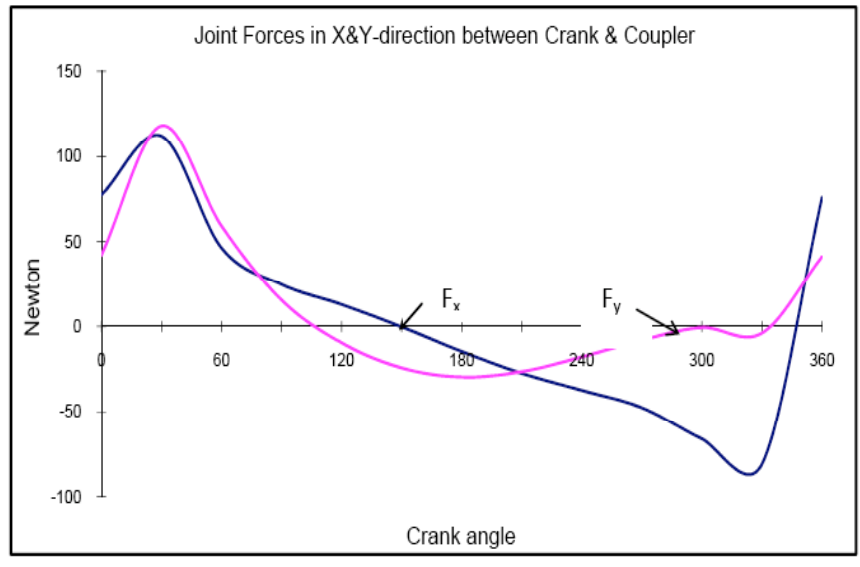

Fig. (20c). Joint forces between Crank and Coupler.

Fig. (20a-c). Graphical representation of Kinematics and Dynamic Analysis.

The significant part of current results, which distinguishes from earlier results, is that in present work exact estimation of mechanical error in coupler point curve is carried out considering clearance link orientations at one and both ends of the coupler. Results of which are shown in Fig. (21).

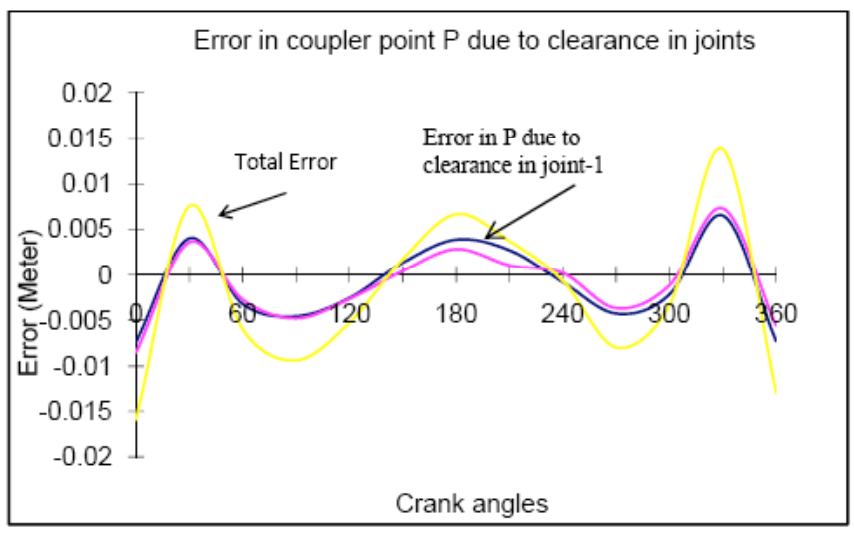

Fig. (21). Error in Coupler point $P$ due to clearances at both ends of coupler. 
Clearance links which are established for $1^{\circ}$ permissible errors in the output angle are used to find out actual error in the output angle considering joint first at only one end and than at both the ends of the coupler. The variation of error is given in Fig. (22a-b). The results show that error is within limit except at few points (close to $0^{\circ}$ crank position), hence the method proposed for finding clearance in joint within permissible error limit in output angle has been validated.

After finding the clearance link, its orientation, error in function and path generation, modal analysis is carried out considering ideal joint i.e. free-free movement and joint with clearance having stiffnesses. The stiffnesses of joint calculated as per the Eqs. 22-25 are transformed in X-Y component using resultant joint force angle and incorporated in the stiffness matrix in $\mathrm{U}_{4}$ and $\mathrm{U}_{5}$ displacement direction as shown in Fig. (15). For torsonal stiffness Eq. 26 is used. Modal analysis is carried out and results are presented in Table 2(a-c) along with Fig. (23a-e). The natural frequencies of the mechanism considering ideal joint are exactly matching with earlier established results for the same mechanism by the ref. [5].

For exact modal analysis of flexible mechanism, joints are added with appropriate linear and torsional stiffness. Finite element approach is used for modal analysis and it is

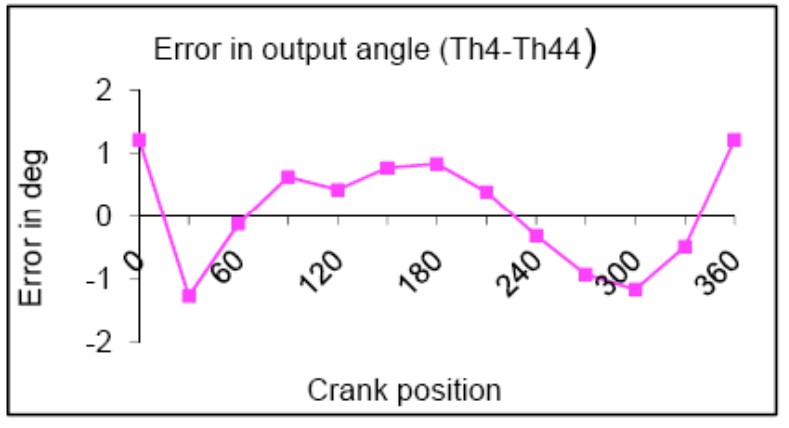

Fig. (22a). Crank Angle vs. Clearance for 1 deg Error in.

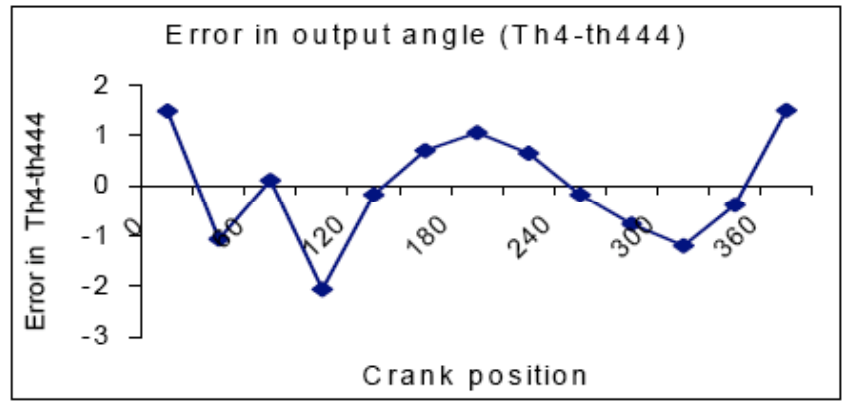

Fig. (22b). Crank Angle vs. Clearance for Output angle 1deg Error in Output angle.

Table 2a. Third Natural Frequencies (Rad/s) Bearing at Joint-1

\begin{tabular}{|c|c|c|c|c|c|c|c|c|c|c|c|c|c|c|}
\hline \multicolumn{2}{|c|}{ Crank Angle (degree) } & $\mathbf{0}$ & 30 & 60 & 90 & 120 & 150 & 180 & 210 & 240 & 270 & 300 & 330 & 360 \\
\hline 1 & 0 & 716 & 1120 & 1300 & 945 & 834 & 924 & 985 & 1060 & 1290 & 1320 & 1230 & 811 & 705 \\
\hline 2 & $4.48 \mathrm{E}+05$ & 715 & 1460 & 1510 & 1520 & 1520 & 1490 & 984 & 1490 & 1510 & 1520 & 1520 & 1440 & 705 \\
\hline 3 & $9.17 \mathrm{E}+05$ & 716 & 1490 & 1520 & 1520 & 1520 & 1510 & 985 & 1510 & 1510 & 1520 & 1520 & 1500 & 706 \\
\hline 6 & $1.06 \mathrm{E}+08$ & 716 & 1520 & 1520 & 1520 & 1520 & 1520 & 992 & 1520 & 1520 & 1520 & 1520 & 1520 & 723 \\
\hline 7 & $6.00 \mathrm{E}+08$ & 715 & 1520 & 1520 & 1520 & 1520 & 1520 & 995 & 1520 & 1520 & 1520 & 1520 & 1520 & 732 \\
\hline 8 & $1.56 \mathrm{E}+09$ & 716 & 1520 & 1520 & 1520 & 1520 & 1520 & 997 & 1520 & 1520 & 1520 & 1520 & 1520 & 733 \\
\hline
\end{tabular}

Table 2b. Fourth Natural Frequencies (Rad/s) Bearing at Joint-1 and 2

\begin{tabular}{|c|c|c|c|c|c|c|c|c|c|c|c|c|c|c|}
\hline \multicolumn{2}{|c|}{ Crank Angle (degree) } & $\mathbf{0}$ & 30 & 60 & 90 & 120 & 150 & 180 & 210 & 240 & 270 & 300 & 330 & 360 \\
\hline 1 & 0 & 1560 & 1600 & 1570 & 1530 & 1520 & 1530 & 1550 & 1590 & 1620 & 1620 & 1530 & 1530 & 1570 \\
\hline 2 & $4.48 \mathrm{E}+05$ & 1560 & 1600 & 1570 & 1530 & 1520 & 1530 & 1550 & 1590 & 1620 & 1620 & 1550 & 1530 & 1570 \\
\hline 3 & $9.17 \mathrm{E}+05$ & 1560 & 1600 & 1580 & 1530 & 1520 & 1530 & 1550 & 1600 & 1620 & 1620 & 1580 & 1530 & 1570 \\
\hline 6 & $1.06 \mathrm{E}+08$ & 1560 & 1620 & 1620 & 1620 & 1620 & 1620 & 1550 & 1620 & 1620 & 1620 & 1620 & 1620 & 1570 \\
\hline 7 & $6.00 \mathrm{E}+08$ & 1560 & 1620 & 1620 & 1630 & 1620 & 1620 & 1550 & 1620 & 1620 & 1620 & 1620 & 1620 & 1570 \\
\hline 8 & $1.56 \mathrm{E}+09$ & 1560 & 1620 & 1620 & 1630 & 1620 & 1620 & 1550 & 1620 & 1620 & 1620 & 1620 & 1620 & 1570 \\
\hline
\end{tabular}


Table 2c. Fifth Natural Frequencies (Rad/s) Bearing at Joint-1

\begin{tabular}{|c|c|c|c|c|c|c|c|c|c|c|c|c|c|c|}
\hline \multicolumn{2}{|c|}{ Crank Angle (degree) } & \multirow{2}{*}{$\mathbf{0}$} & \multirow{2}{*}{30} & \multirow{2}{*}{60} & \multirow{2}{*}{90} & \multirow{2}{*}{120} & \multirow{2}{*}{150} & \multirow{2}{*}{180} & \multirow{2}{*}{210} & \multirow{2}{*}{240} & \multirow{2}{*}{270} & \multirow{2}{*}{300} & \multirow{2}{*}{330} & \multirow{2}{*}{360} \\
\hline S. No. & Stiffness (N/m) & & & & & & & & & & & & & \\
\hline 1 & 0 & 1820 & 1980 & 1750 & 1690 & 1670 & 1680 & 1690 & 1730 & 1970 & 1910 & 1720 & 1740 & 1830 \\
\hline 2 & $4.48 \mathrm{E}+05$ & 1820 & 3290 & 4890 & 3880 & 3030 & 2080 & 1690 & 2890 & 5540 & 6190 & 4290 & 2080 & 1830 \\
\hline 3 & $9.17 \mathrm{E}+05$ & 1820 & 4230 & 6520 & 5340 & 4180 & 2710 & 1690 & 3840 & 7160 & 7860 & 5820 & 2620 & 1830 \\
\hline 4 & $1.23 \mathrm{E}+07$ & 1820 & 9480 & 10600 & 10700 & 10400 & 8050 & 1690 & 9320 & 10600 & 10800 & 10600 & 7490 & 1830 \\
\hline 5 & $8.00 \mathrm{E}+07$ & 1820 & 10700 & 11000 & 11000 & 10900 & 10600 & 1690 & 10600 & 10900 & 11000 & 10900 & 10400 & 1830 \\
\hline 6 & $1.06 \mathrm{E}+08$ & 1820 & 10700 & 11000 & 11000 & 11000 & 10700 & 1690 & 10700 & 11000 & 11000 & 10900 & 10500 & 1830 \\
\hline 7 & $6.00 \mathrm{E}+08$ & 1820 & 10800 & 11000 & 11000 & 11000 & 10800 & 1690 & 10800 & 11000 & 11000 & 11000 & 10800 & 1830 \\
\hline 8 & $1.56 \mathrm{E}+09$ & 1820 & 10800 & 11000 & 11000 & 11000 & 10800 & 1690 & 10800 & 11000 & 11000 & 11000 & 10800 & 1830 \\
\hline
\end{tabular}

observed that for first and second natural frequency, the difference in the magnitude of frequencies with ideal joint and joint with stiffness $1.56 \mathrm{E} 9 \mathrm{~N} / \mathrm{m}$ is minimal and can be neglected. However, third natural frequency for ideal joint is varying from $716 \mathrm{rad} / \mathrm{s}$ to $1320 \mathrm{rad} / \mathrm{s}$ and for joint with equivalent stiffness of $1.56 \mathrm{E} 9 \mathrm{~N} / \mathrm{m}$ is varying from $760 \mathrm{rad} / \mathrm{s}$ to $1520 \mathrm{rad} / \mathrm{s}$. There is maximum difference of approximately $760 \mathrm{rad} / \mathrm{s}$. As regards to the fifth natural frequency for ideal joint, is varying from $1670 \mathrm{rad} / \mathrm{s}$ to $1980 \mathrm{rad} / \mathrm{s}$. and for joint with equivalent stiffness of $1.56 \mathrm{E} 9 \mathrm{~N} / \mathrm{m}$ is varying from $1690 \mathrm{rad} / \mathrm{s}$ to $11000 \mathrm{rad} / \mathrm{s}$. There is a maximum difference of approximately 9300rad/s Table 2(a-c) and Fig. (23a-e).

In the Table, natural frequencies are given for different values of stiffness assigned to the clearances, varying from $4.48 \mathrm{E} 5$ to $1.56 \mathrm{E} 9 \mathrm{~N} / \mathrm{m}$.

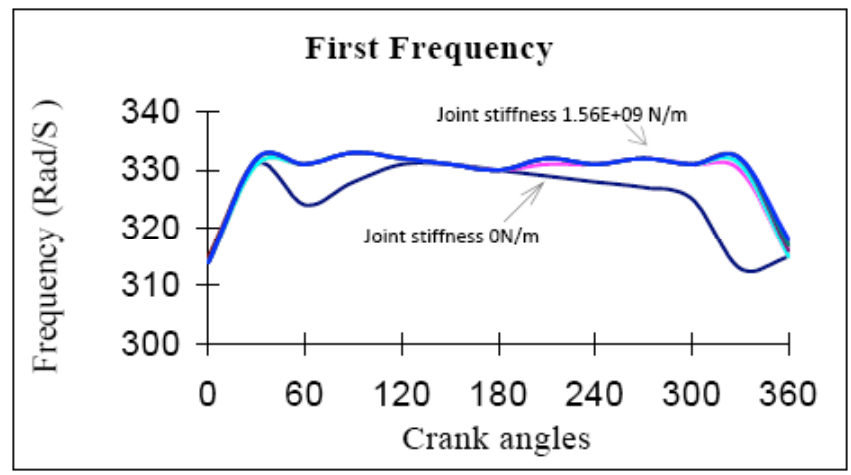

Fig. (23a).

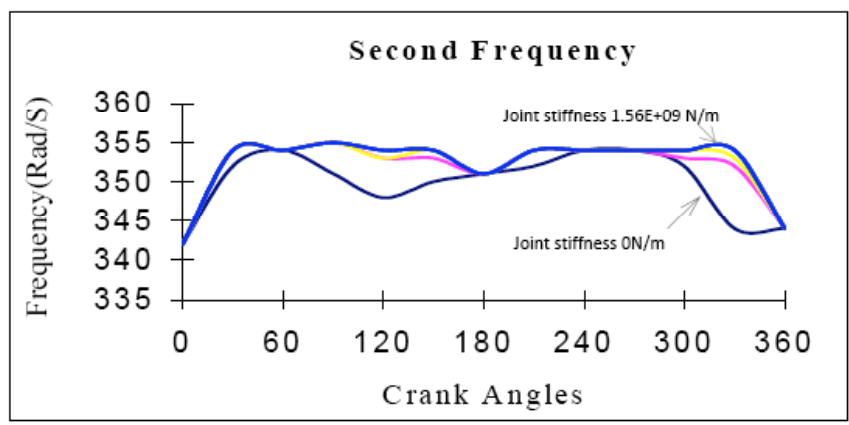

Fig. (23b).

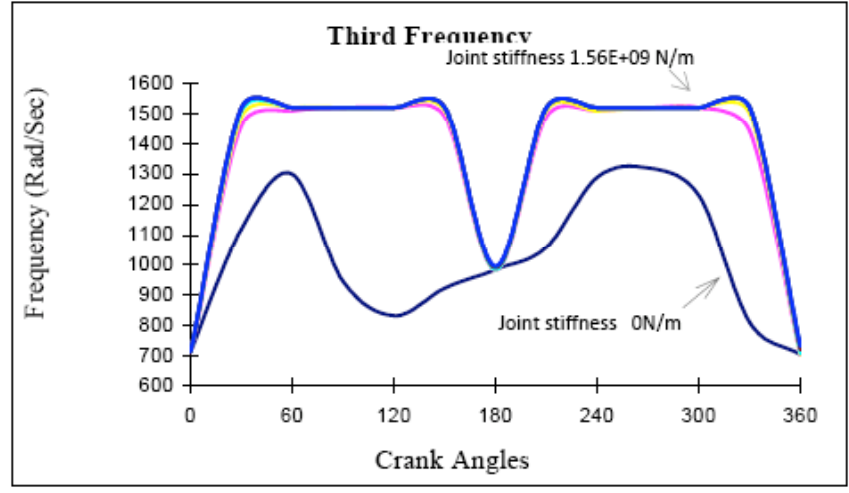

Fig. (23c).

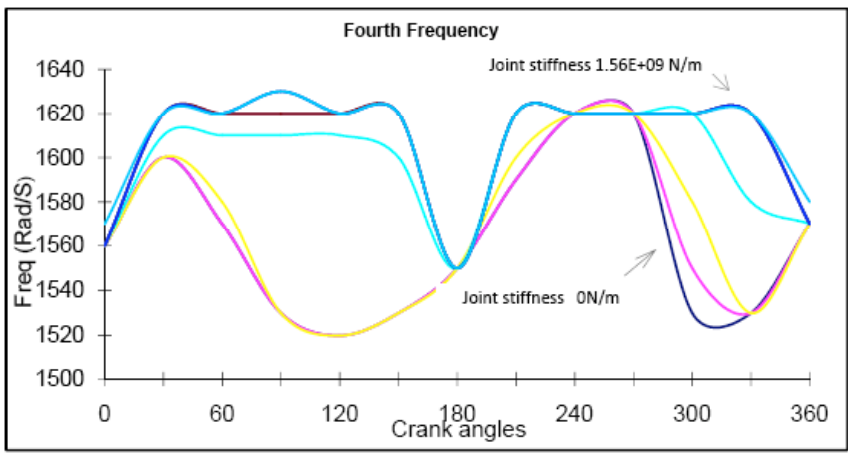

Fig. (23d).

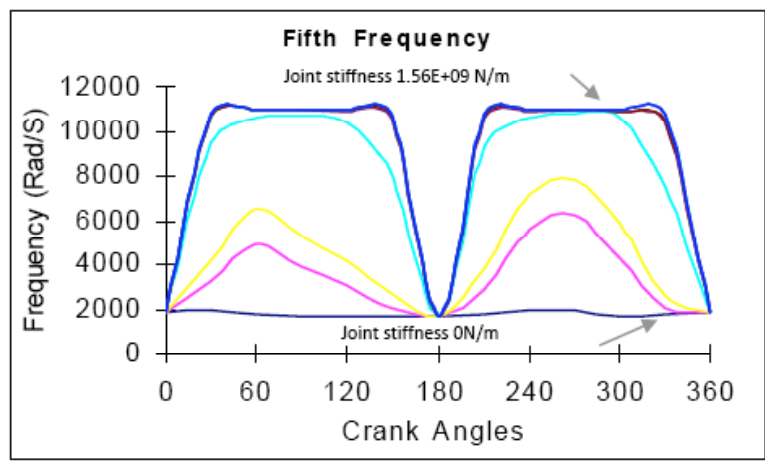

Fig. (23e). Fifth Natural frequency.

Fig. (23a-e). Frequencies considering Bearing Stuffiness between Crank-Coupler. 

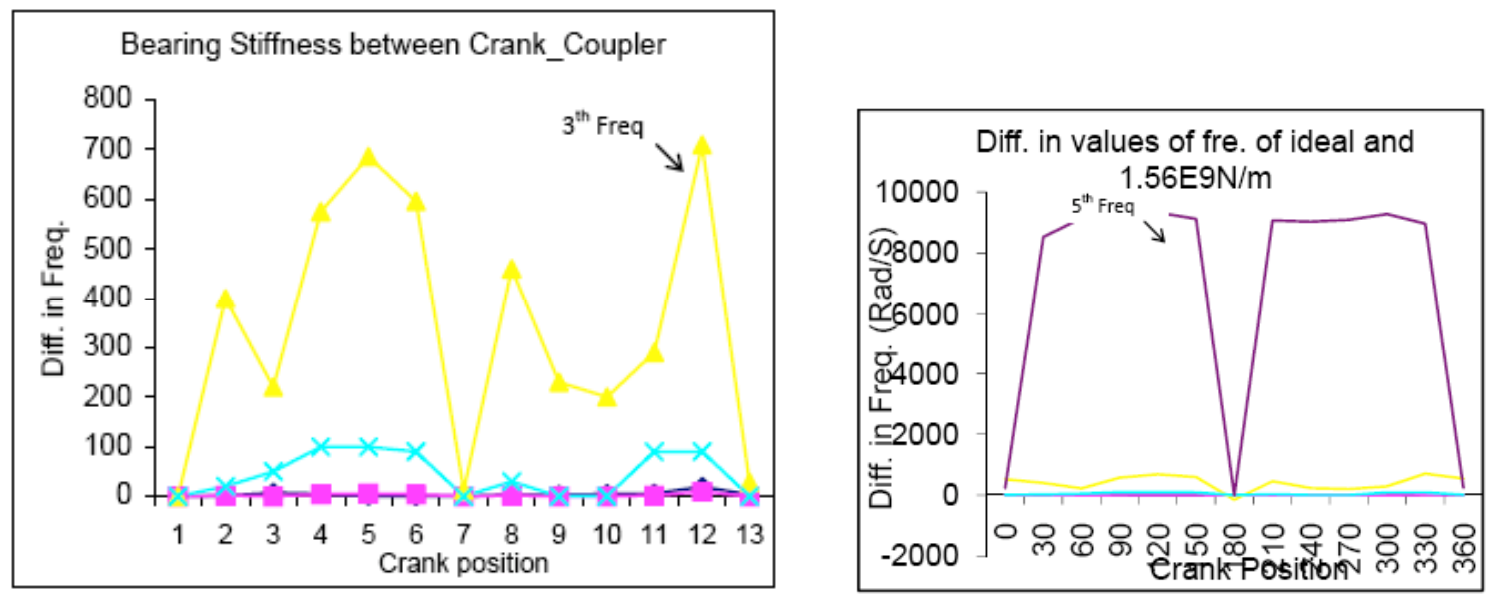

Fig. (24a-b). Difference in Ideal Joint and Joint with Stiffness.

It is observed that as the stiffness of joint is increased from $4.5 \times 10^{5} \mathrm{~N} / \mathrm{m}$ to $1.6 \times 10^{9} \mathrm{~N} / \mathrm{m}$, natural frequency also increases and converges when stiffness reaches approximately to $1.56 \mathrm{E} 9 \mathrm{~N} / \mathrm{m}$. This is expected and also justified by the earlier work $[5,6]$. Fig. (24a-b) also indicate that for higher frequencies the difference increases drastically for Third and Fifth frequency. This fact indicates that the effect of bearing stiffness be incorporated in the analysis of flexible linkages operating at higher frequencies to get the actual performance and to study the natural frequencies due to change in stiffness of bearing due to wear, out of run, play etc during operation.

The mid point coupler bending strain are obtained for ninety equal crank angle positions shown in Fig. (25). Bending strain and elemental joint forces are minimum from $60^{\circ}$ to $288^{\circ}$ crank angle where the transmission angle is within recommended range $\left(90^{\circ} \pm 40^{\circ}\right)$ as shown in Fig. (26).

Figs. (25 and 26) show coupler mid point bending strain at $340 \mathrm{rpm}$ varying from $-9.38 \times 10^{-4}$ to $8.31 \times 10^{-4}$ Meter/ Meter. The magnitude of bending strain and therefore stress is minimum for optimum transmission angles and matches with [15]. Optimum transmission variation in the strain with crank angle is also crossed checked with the earlier researcher.

\section{CONCLUSION}

In this paper, error in coupler point location and output angle of a four bar mechanism due to clearance link orientation at one end and both ends of coupler is examined. Finite element approach is carried out for modal analysis for linkage and joint flexibility. The study reveals following conclusions:

- For four bar mechanism the coupler point location and output angle is greatly affected by joint clearances and flexibility in linkages.

- The error in the output angle and coupler position is minimum for optimal transmission angles.

- In four bar mechanism joints can be exactly modeled with the help of clearance link assigned with proper

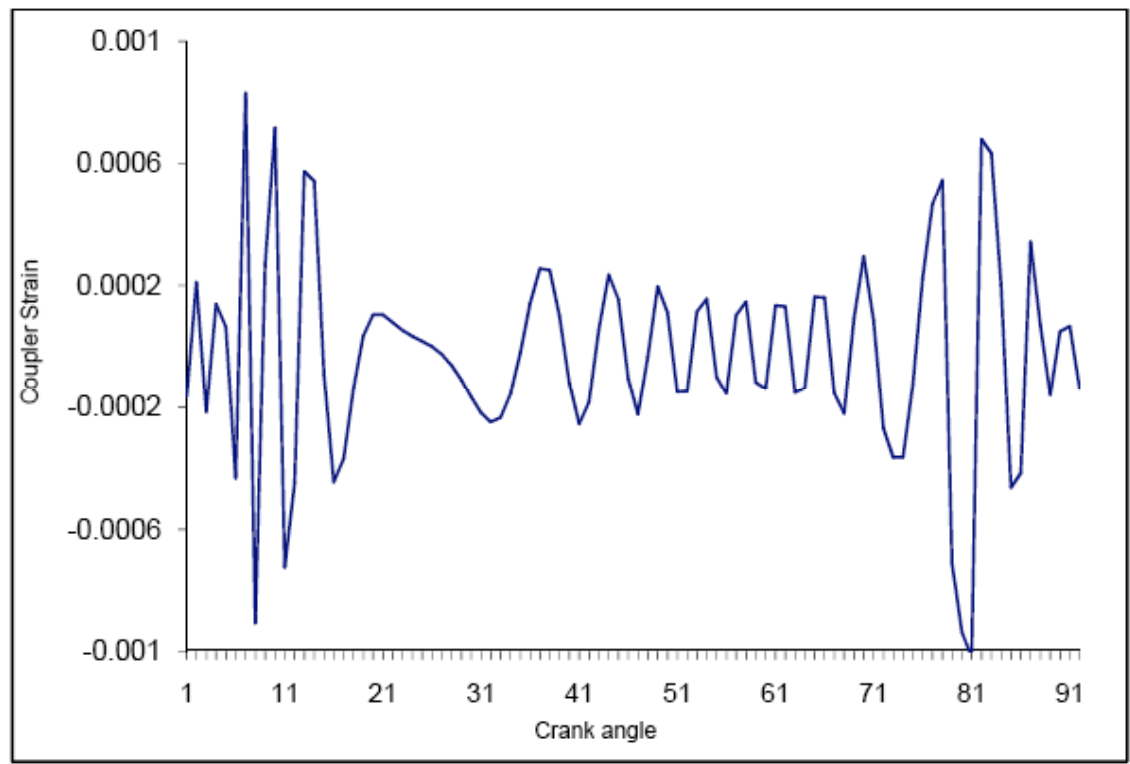

Fig. (25). Coupler mid point bending strain. 


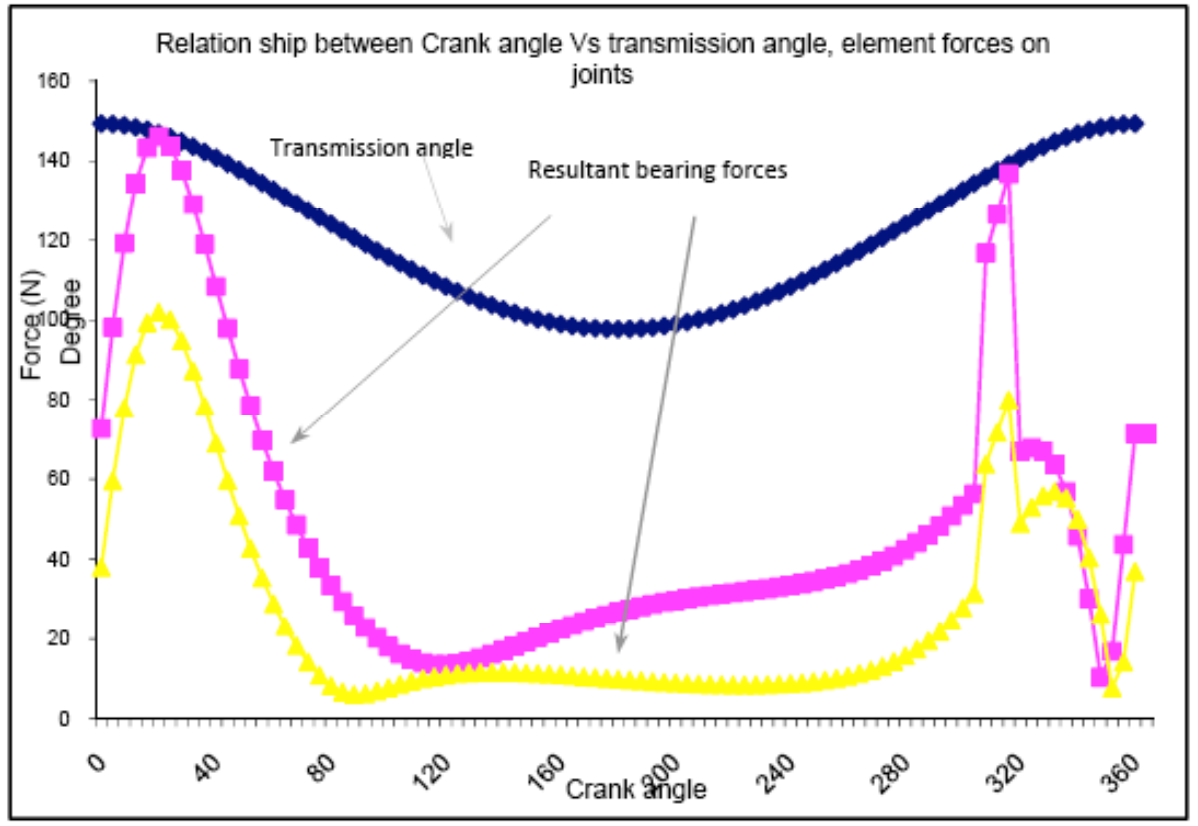

Fig. (26). Transmission angle and elemental joint forces.

axial, longitudinal and torsional stiffness.

- Joint stiffness does affects the model analysis of the four bar mechanism especially at higher order frequencies.

\section{REFERENCES}

[1] G. Gilardi, and I. Sharf, "Literature survey of contact dynamics mode-ling," Mechanism and Machine Theory, vol. 37, no. 10, pp. 1213-1239, 2002.

[2] P. Flores, J. Ambro'sio, J.C.P. Claro, H.M. Lankarani, and C.S. Koshy, "A study on dynamics of mechanical systems including joints with clearance and lubrication," Mechanism and Machine Theory, vol. 41, pp. 247-261, 2006.

[3] A.L. Schwab, J.P. Meijaard, and P. Meijers, "A comparison of revolute joint clearance model in the dynamic analysis of rigid and elastic mechanical systems," Mechanism and Machine Theory, vol. 37, no. 9, pp. 895-913, 2002.

[4] S.K. Dwivedy, and P. Eberhard, "Review dynamic analysis of flexible manipulators, a literature review," Mechanism and Machine Theory, vol. 41, pp. 749-777, 2006.

[5] D.A. Turcic, and A. Midha, "Dynamic analysis of elastic mechanism systems. Part I: Applications, measurement and control," Journal of Dynamic Systems, vol. 106, pp. 249-254, 1984.

[6] D.A. Turcic, A. Midha, and J.R. Bosnik, "Dynamic analysis of elastic mechanism systems. Part II: Experimental Results measurement and control," Journal of Dynamic Systems, vol. 106, pp. 255-260, 1984.
[7] S.D. Yu, and F. Xi, "Free Vibration analysis of planar flexible mechanisms," Journal of Mechanical Design, vol. 125, 764-772, 2003.

[8] S.D. Yu, and W.L. Cleghorn, "Dynamic instability analysis of high-speed flexible four-bar mechanisms," Mechanism and Machine Theory, vol. 37, pp. 1261-1285, 2002.

[9] K.-L. Ting, J. Zhu, and D. Watkins, "The effect of joint clearance on the position and orientation deviation of linkages and manipulators," Mechanism and Machine Theory, vol. 35, pp. 391401, 2000.

[10] J.K. Shin, and J.H. Jung, "On the mechanical errors in planar linkages," Mechanism and Machine Theory, vol. 97, pp. 378-382, 1997.

[11] A.M. Vaidya, and P.M. Padole, "Error analysis of four bar planar mechanism considering clearance between crank \& coupler," In: $13^{\text {th }}$ National Conference on Mechanisms and Machines (NaCoMM07), IISc, Bangalore: India, December 2007, pp. 12-13.

[12] R.S. Balupari, "Validation of finite element program for journal bearing- static and dynamic properties," MS thesis, College of engineering, University of Kentucky, Lexington, UK 2004.

[13] J. Rhee, and A. Akay, "Dynamic response of a revolute joint with clearance", Mechanism and Machine Theory, vol. 31, pp. 121-134, 1996.

[14] L.L. Howell, and A. Midha, "Parametric deflection approximation for end-loaded, large-deflection beams in compliant mechanisms," Journal of Mechanical Design, Transaction, ASME, vol. 11 no. 1, pp. 156-165, 1995.

[15] Z. Yang, and J.P. Sadler, "Large-displacement finite element analysis of flexible linkages," Journal of Mechanical Design, vol. 112, pp. 175-182, 1990 .

(C) Vaidya and Padole; Licensee Bentham Open.

This is an open access article licensed under the terms of the Creative Commons Attribution Non-Commercial License (http: //creativecommons.org/licenses/by$\mathrm{nc} / 3.0 /$ ), which permits unrestricted, non-commercial use, distribution and reproduction in any medium, provided the work is properly cited. 